Fearing Fear: Gender and Economic Discourse

Julie A. Nelson

WORKING PAPER 2013-04

DEPARTMENT OF ECONOMICS

UNIVERSITY OF MASSACHUSETTS BOSTON 


\title{
Fearing Fear: Gender and Economic Discourse
}

\begin{abstract}
:
Economic discourse-or the lack of it-about fear is gendered on at least three fronts. First, while masculine-associated notions of reason and mind have historically been prioritized in mainstream economics, fear-along with other emotions and embodiment-has tended to be culturally associated with femininity. Research on cognitive "gender schema," then, may at least partly explain the near absence of discussions of fear within economic research. Second, in the rare cases where fear is discussed in the contemporary economics literature, there is a tendency to (overly-)strongly associate it with women. Finally, historians and philosophers of science have suggested that the failure to consider the full range of human emotions and experience may be itself rooted in fear: a fear of the feminine. This aversion to discussing fear-especially fear as experienced by men-may contribute to serious problems, especially in regard to financial market instability and ecological threats.
\end{abstract}

Keywords: Cognitive Schema, Fear, Gender, Risk Aversion, Stereotypes 


\section{Introduction}

Economic discourse - or the lack of it—about fear is gendered on at least three fronts. First, while masculine-associated notions of reason, mind, choice, control, and mechanism have historically been prioritized in mainstream economics, fear-along with other emotions, embodiment, vulnerability, and lived experience-has tended to be feminine-associated. Contemporary psychological and neuroscientific research on cognitive "gender schema," then, may at least partly explain the near absence of discussions of fear within economic research. Second, in the rare cases where fear is discussed in the economics literature, there is a tendency to (overly-) strongly associate it with women. Finally, dominant Western cultural metaphors not only associate fear with femininity, but also with inferiority and a lack of control. Historians and philosophers of science have suggested that failures to acknowledge the full range of human emotions and experience may be themselves be rooted in fear: a fear of the feminine.

This essay discusses these three gendered aspects of the relationship between the economics discipline and fear, and concludes with a brief discussion of the problems created. Economists' aversion to discussing fear-especially fear as experienced by men - seriously hampers the discipline's ability to make create useful knowledge in the face of financial market instability and ecological threats.

\section{Removing (Feminine) Emotions from Economics}

Findings from cognitive psychology, social psychology, evolutionary biology, neuroscience, and related scientific fields have recently been drawn on to enrich economists' study of human behavior. One outgrowth of the study of how evolved, embodied humans actually think-as opposed to how a purely rational being would think-is discussion of the role of "cognitive schema," or unconscious ways in which we process stimuli using mental groupings. Psychological and neuroscientific research show that cognitive schemas are important ways in which we "organize incoming information and integrate it—-through no conscious act of will-into 
clusters" (e.g., Most, Sorber et al. 2007, 288), speeding up processing and economizing on mental effort.

The gender binary - that is, the association of a stimulus with either masculinity or femininity-is apparently a fundamental cognitive schema by which we often split the world into two categories. It has been confirmed in a number of studies in cognitive science that we process things more easily and quickly if they fit our mental gender constructs, and have to work more if they do not. For example, subjects tend to take longer and make more mistakes when, for example, a male name is read by a female voice than when a male name is read by a male voice (Most, Sorber et al. 2007); remember lists of words better when words on a list all have the same gender connotation than when they are mixed or neutral (Bem 1981); and have to think longer when a task involves overriding stereotyped associations between gender and strength or weakness (Knutson, Mah et al. 2007), or the gender associations of various academic fields (Nosek, Banaji et al. 2007). These studies suggest that these automatic associations are strong, and without considerable conscious effort and new experiences, may tend to exert considerable invisible power over the way we think.

By the early 1990s, a number of commentators (McCloskey 1985; Nelson 1992; Jennings 1993) had noticed that mainstream economics had formed in close adherence to the "masculine" side of many cultural binaries. Consider Table 1. Within neoclassical orthodoxy, economics is generally taken to be defined by concern with markets, choice, or both. Women's historical experiences in families, tending to the day-to-day bodily needs of people for food and care, are not studied. The economic agent of neoclassical theory is autonomous, self-interested and rational--characteristics that have a long history of association with men and masculinity in Western culture. Interdependence, other-interest, and emotion are, in contrast, culturally coded as feminine. Abstract mathematical methods are favored, while verbal or qualitative knowledge is referred to as (presumably less reliable) "intuition." Note that this sort of table is by no means meant to reinforce the idea that men are "really" more rational, or women are "really" more emotional; it refers 
to commonly shared cognitive associations within a specific (dominant Western) cultural context.

Table 1: Splitting the World: Schemas in Mainstream Economics

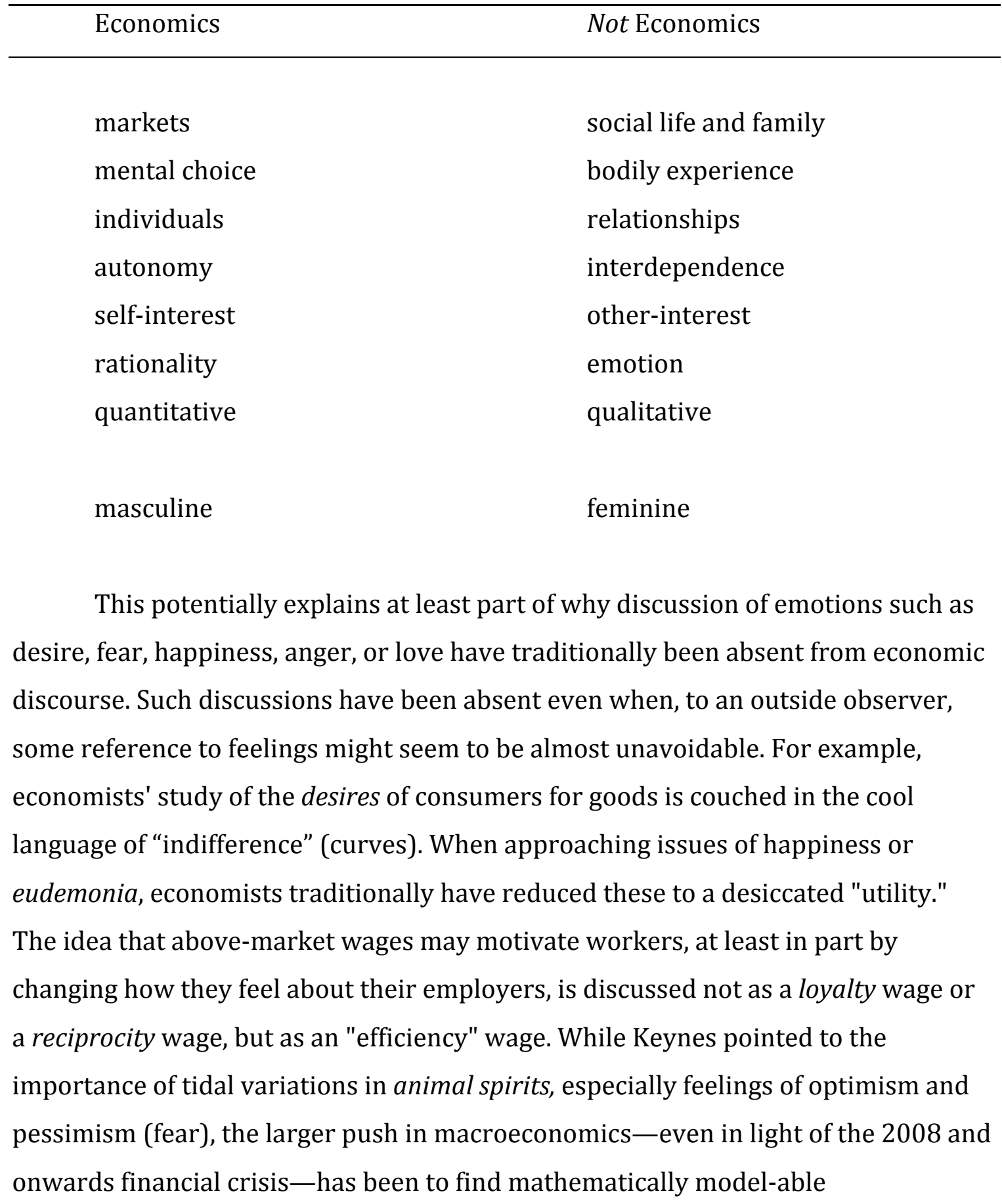


"mechanisms" underlying (presumably fundamentally cool and well-ordered) macroeconomic systems.

The avoidance of discussion of fear is particularly notable in recent economics studies of risk aversion. While many scholars outside of economics note that emotions, including fear, play an important role in risk-related perceptions and choices (e.g., Lopes 1987; Olsen and Cox 2001; Kahan, Braman et al. 2007; Carr and Steele 2010), and recognize that that emotions are, in fact, an important and necessary component of cognition and reasonable behavior (Damasio 1994), this seems to be less the case among economists. The economics literature tends to manifest a more abstract and bloodless analysis, portraying risk aversion as a parameter in a mathematical utility function. Even behavioral economists seem to write whole studies about risk or loss aversion without much mentioning emotions (Novemsky and Kahneman 2005; Bruhin, Fehr-Duda et al. 2010), or labeling emotions of aversion as "fear" (Sokol-Hessner, Camerer et al. 2013 (March, online publication)).

Economist Colin Camerer's "intuition is that loss aversion is often an exaggerated emotional reaction of fear" (Camerer 2005, 132) seems to be a rare exception. While it stands in stark contrast to economists' traditional, disembodied, expected-utility-theory axiomatic approach, Camerer's "intuition" is actually a perfectly logical supposition that is also strongly empirically-supported by research in evolutionary psychology, neuroscience, and prospect theory.

Camerer has also (apparently) raised the question "Why are economists so aversion averse" (Google 2013). But combining his question about economists with his "intuition" about aversion leads to an perhaps uncomfortable inference: Economists own behavior may reflect bodily experiences of fear. ${ }^{1}$ We will return to this question in Section 4.

${ }^{1}$ Perhaps this discomfort explains why Camerer's question appears as the title of a link in a Google search, but the link now goes to a paper with a different and less provocative title (working paper version of Camerer 2005). 


\section{Associating Fear with Women}

Economists seem to display somewhat more enthusiasm for acknowledging the possible emotional basis of risk aversion when these responses can be associated with women, to a greater degree than with men. Such a position is quite consistent with the cognitive splitting of the world just discussed, and is apparent in many examples in the recent literature.

"We find that women are indeed more risk averse than men," conclude economists Rachel Croson and Uri Gneezy $(2009,448)$ in their JEL review article "Gender Differences in Preferences." There is "Strong Evidence for Gender Differences in Risk Taking," claim Gary Charness and Uri Gneezy in JEBO (2012). Croson and Gneezy cite, as a possible explanation, studies that report that "women report more intense nervousness and fear than men in anticipation of negative outcomes," while men feel more anger $(2009,452)$. Other articles also make links between risk aversion and claims about women's stronger emotionality (Fehr-Duda, Gennaro et al. 2006, 306; Eriksson and Simpson 2010, 162). The idea that

fundamentally different biology and neurological structures may be the source of differences in male and female psycho-social behaviors has recently had a resurgence in general academic and popular thought (e..g, Baron-Cohen 2003).

Could these results, also or in part, however, be the result of world-splitting unconscious gender schema and stereotypes held by the researchers and/or the research subjects? The psychological phenomenon of confirmation bias leads people to pay more attention to arguments and evidence that support what they already believe, and less to conflicting information. As human beings, academic researchers are not immune to influence by prior beliefs, including gender stereotypes. Nickerson's (1998) review of the confirmation bias literature, for example, provides numerous examples of this phenomenon affecting scientific fields. Another recent study found that the more one feels that one is an "objective, rational actor," the more likely one is to have confidence in one's stereotyped beliefs and act on them (Uhlmann and Cohen 2007). In regard to emotions, recent studies have noted that people often make attributions of emotions in gender-stereotyped ways, even when 
the portrayals of emotion are ambiguous (Plant, Hyde et al. 2000; Johnson, McKay et al. 2011). Most emotions, including fear, are stereotypically associated with women; only pride and anger are more strongly associated with men (Plant, Hyde et al. 2000, 83).

A number of scholars have pointed out flaws in the psychological and neurological research that claims to find strong (stereotyped) gender differences in psycho-social behavior (e.g., Hyde 2005; Fine 2010; Jordan-Young 2010), suggesting that such conclusions go well beyond what can actually be claimed based on empirical evidence. Investigating these issues in the context of economic studies regarding risk, Julie Nelson (2012) finds a number of weaknesses in the claim that "women are more risk averse than men." Most crucially, statistical significance seems to have often been confused with substantive significance, there is evidence of publication bias, and the fact of very considerable intra-sex variation seems to largely be overlooked. It may be that economists' attribution of greater emotionality and fear to women is as much or more an outcome of a prior belief in the "unmanliness" of such a response to threats and opportunities, as the outcome of empirical study.

\section{Fear of the Feminine}

The roots of the "fear of fear" in economics may be older and more farreaching than the analysis so far has suggested. The strong binary gendering that underlies historical and many contemporary images of science has been brought to light by a number of historians and philosophers (e.g., Easlea 1980; Keller 1985; Harding 1986; Plumwood 1993). They pointed out how binaries such as man/nature, mind/body, activity/passivity, order/chaos, separation/connection, and male/female strongly influenced the Western conception of the order of the world. This metaphorical structure is not only dualistic; it is also hierarchical, with masculinity taking the high-value pole. From Plato and Aristotle, through Descartes and Bacon, the image of knowledge as the masculine means to firmly control a dangerous feminine Nature emerged. 
"The Cartesian 'masculinization of thought,'" Susan Bordo has written, "is one intellectual 'moment' of an acute historical flight from the feminine, from the memory of union with the maternal world, and a rejection of all values associated with it" (Bordo 1987, 9). James Hillman has written, "The specific consciousness we call scientific, Western and modern is the long sharpened tool of the masculine mind that has discarded parts of its own substance, calling it 'Eve,' 'female' and 'inferior'" (quoted in Bordo 1986, , 441). The counterpoint to "rational man," Elizabeth Fee has pointed out, is "woman [who] provides his connection with nature; she is the mediating force between man and nature, a reminder of his childhood, a reminder of the body, and a reminder of sexuality, passion, and human connectedness" (Fee 1983,12 ). Since bodies are far more vulnerable, mortal, and messy than the pure Cartesian cogito, contemplation of the feminine-associated aspects of human life may create anxiety. It may therefore be avoided.

Contemporary psychological research also sheds light on this issue. Male "gender role conflict" has been thought to arise from "socialized gender roles learned in sexist and patriarchal societies" (O'Neil 2008, 362) and be related to issues of control and power (361). It is said to result in a "fear of femininity" as well as "cognitive distortions" (O'Neil 2008, 362, 365). Kahan, Braman et al. (2007) have investigated intersections of sex, race, and cultural worldviews, and found that the largest differences in risk perception tend to be, not between men and women, but between white males who have hierarchical and individualist world views and most everyone else. While both the desire to, and the ability to, imagine oneself as separate from others and in control has been assumed to be universal in much liberal Western philosophy and economics (Meagher and Nelson 2004), these may be much more highly culture-specific traits than those literatures suggest.

The contemporary economics literature on risk aversion also tends to reflect the hierarchical nature of dominant gender metaphors, with men and fearlessness on the high-valued pole: Higher risk aversion is generally regarded as something negative. Greater risk aversion is associated with an inability to "rationally" play lottery experiments (in an expected utility sense); with inadequate retirement portfolios (Bernasek and Shwiff 2001; Arano, Parker et al. 2010, 147), with 
neuroticism and a lack of ambition (Borghans, Golsteyn et al. 2009, 655); with an inability to advance in employment or entrepreneurship (Hartog, Ferrer-i-Carbonell et al. 2002, 24; Lindquist and Säve-Söderbergh 2011, 158; Booth and Nolen 2012, F56). Women are, in fact, encouraged to become more like men in their risk preferences, in order to succeed in "modern societies" (Eckel and Grossman 2002, 291).

Feeling, expressing, or even recognizing the existence of fear (except, perhaps, in women) seems, then, to be often associated with inferiority and emasculation. Recognizing and engaging with issues of fear, other emotions, and human connection-on the part of us as researchers, ourselves, as well as in our research subjects-might seem, in particular, to threaten economists' traditional stance of "objectivity." Yet the notion that objectivity is somehow guaranteed by a position of cool abstraction, detachment, and adherence to strict mathematical logic has been challenged by numerous philosophers of science (e.g., Keller 1985; Longino 1990; Sen 1992; Kitcher 2011). While mathematical rigor gives a model internal consistency, this is a very different thing from giving it validity in explaining real-world phenomena. A much more sensible notion of objectivity defines reliable knowledge as that which passes the test of evaluation by larger communities (e.g., Keller 1985; Longino 1990; Sen 1992; Kitcher 2011).

\section{Problems and Solutions}

The association of fear with femininity may help explain why emotions of fear, though so important in real world phenomena such as financial panics, have remained under-studied. To the extent that fear is deeply and unconsciously associated with the "feminine" realm, its presence and significance in realms such as masculine-associated markets and the masculine-associated economics discipline will tend to be automatically denied.

This creates problems. An obvious one is one of bias: Phenomena such as fear may be dismissed merely because they do not fit our gender-schematic image of how the world works, even when they are important explanatory factors in explaining real-world economic events. A second problem is that our actions-as 
economists, and as actors in the economy-may be biased towards excessive risktaking. Too little risk aversion, it has been noted in the psychology literature, may be associated with "unrealistic illusions of control" that "suppress the feelings of anxiety that might otherwise serve to warn of danger" (Ronay and Kim 2006, 413). The excessive financial risks taken on by large financial institutions in the years leading up to 2008 may be one example. A lack of urgency in dealing with the problem of climate change may be another.

Economic discourse might, presumably, be somewhat improved by bringing in discussion of the topic of fear while still maintaining a disciplinary allegiance to images of (mostly) rational "economic man," a focus on choice behavior, and the (extremely questionable) notion that disciplinary objectivity is assured through a reliance on mathematical modeling. Considering the neglect of fear to be but one among a whole network of gendered, harmful biases, however, suggests that improvements could be more far-reaching. We could adopt a fuller and richer understanding of human behavior, as well as more comprehensive set of research methods. The resulting changes in economic discourse could make our discipline more helpful for addressing the threats and opportunities continually thrown up by our world - a world that is not, in fact, under our control.

\section{References}

Arano, Kathleen, Carl Parker, et al. (2010). "Gender-Based Risk Aversion and Retirement Asset Allocation." Economic Inquiry 48(1): 147-155.

Baron-Cohen, Simon (2003). The Essential Difference: The Truth about the Male and Female Brain. NY, Basic Books.

Bem, Sandra Lipsitz. (1981). "Gender Schema Theory: A Cognitive Account of Sex Typing." Psychological Review 88(4): 354-364.

Bernasek, Alexandra and Stephanie Shwiff (2001). "Gender, Risk, and Retirement." Journal of Economic Issues 35(2): 345-356.

Booth, Alison L. and Patrick Nolen (2012). "Gender Differences in Risk Behaviour: Does Nurture Matter?" The Economic Journal 122(558).

Bordo, Susan (1986). "The Cartesian Masculinization of Thought." Signs: Journal of Women in Culture and Society 11(3): 439-456.

Bordo, Susan (1987). The Flight to Objectivity. Albany, State University of New York Press. 
Borghans, Lex, Bart H. H. Golsteyn, et al. (2009). "Gender Differences in Risk Aversion and Ambiguity Aversion." Journal of the European Economic Association 7(2-3): 649-658.

Bruhin, Adrian, Helga Fehr-Duda, et al. (2010). "Risk and Rationality: Uncovering Heterogeneity in Probability Distortion." Econometrica 78(4): 1375-1412.

Camerer, Colin (2005). "Three Cheers-Psychological, Theoretical, Empirical-for Loss Aversion." Journal of Marketing Research 42(2): 129-133.

Carr, Priyanka B. and Claude M. Steele (2010). "Stereotype Threat Affects Financial Decision Making." Psychological Science 21: 1411-1416.

Charness, Gary and Uri Gneezy (2012). "Strong Evidence for Gender Differences in Risk Taking." Journal of Economic Behavior \& Organization 83(1): 50-58.

Croson, Rachel and Uri Gneezy (2009). "Gender Differences in Preferences." Journal of Economic Literature 47(2): 448-474.

Damasio, Antonio R. (1994). Descartes' Error: Emotion, Reason, and the Human Brain. New York, G.P. Putnam's Sons.

Easlea, Brian (1980). Witch Hunting, Magic and the New Philosophy: An Introduction to Debates of the Scientific Revolution, 1450-1750. Atlantic Highlands, NJ, Humanities Press.

Eckel, Catherine C. and Philip J. Grossman (2002). "Sex differences and statistical stereotyping in attitudes toward financial risk." Evolution and Human Behavior 23: 281-295.

Eriksson, Kimmo and Brent Simpson (2010). "Emotional reactions to losing explain gender differences in entering a risky lottery." Judgment and Decision Making 5(3): 159-163.

Fee, Elizabeth (1983). Women's nature and scientific objectivity. Women's Nature: Rationalizations of Inequality. M. Lowe and R. Hubbard. New York, Pergamon Press: 9-27.

Fehr-Duda, Helga, Manuele De Gennaro, et al. (2006). "Gender, Financial Risk, and Probability Weights." Theory and Decision 60: 283-313.

Fine, Cordelia (2010). Delusions of Gender: How Our Minds, Society, and Neurosexism Create Difference. NY, W.W. Norton.

Google. (2013). "Googe search for "Camerer risk aversion" " Retrieved Sept. 6, 2013.

Harding, Sandra (1986). The Science Question in Feminism. Ithaca, Cornell University Press.

Hartog, Joop, Ada Ferrer-i-Carbonell, et al. (2002). "Linking Measured Risk Aversion to Individual Characteristics." Kyklos 55(1): 3-26.

Hyde, Janet Shibley (2005). "The Gender Similarities Hypothesis." American Psychologist 60(6): 581-592.

Jennings, Ann L. (1993). Public or Private? Institutional Economics and Feminism. Beyond Economic Man. M. A. Ferber and J. A. Nelson. Chicago, University of Chicago Press: 111-129.

Johnson, K. L., L. McKay, et al. (2011). "Why "He throws like a girl" (but only when he's sad): Emotion affects sex-decoding of biological motion displays." Cognition 119: 265-280. 
Jordan-Young, Rebecca M. (2010). Brain Storm: The Flaws in the Science of Sex Differences. Cambridge, Harvard University Press.

Kahan, Dan M., Donald Braman, et al. (2007). "Culture and Identity-Protective Cognition: Explaining the White-Male Effect in Risk Perception." Journal of Empirical Legal Studies 4(3): 465-505.

Keller, Evelyn Fox (1985). Reflections on Gender and Science. New Haven, Conn., Yale University Press.

Kitcher, Philip (2011). Science in a Democratic Society Prometheus Books.

Knutson, Kristine M., Linda Mah, et al. (2007). "Neural Correlates of Automatic Beliefs About Gender and Race." Human Brain Mapping 28: 915-930.

Lindquist, Gabriella Sjögren and Jenny Säve-Söderbergh (2011). "“Girls will be Girls", especially among Boys: Risk-taking in the "Daily Double" on Jeopardy." Economics Letters 112(2): 158-160.

Longino, Helen (1990). Science as Social Knowledge: Values and Objectivity in Scientific Inquiry. Princeton, NJ, Princeton University Press.

Lopes, Lola L. (1987). Between hope and fear: The psychology of risk. Advances in experimental social psychology. L. Berkowitz. New York, Academic Press. 20: 255-295.

McCloskey, Daniel N. (1985). The Rhetoric of Economics. Madison, WI, University of Wisconsin Press.

Meagher, Gabrielle and Julie A. Nelson (2004). "Survey Article: Feminism in the Dismal Science." Journal of Political Philosophy 12(1): 102-126.

Most, Steven B., Anne Verbeck Sorber, et al. (2007). "Auditory Stroop reveals implicit gender associations in adults and children." Journal of Experimental Social Psychology 43(2): 287-294.

Nelson, Julie A. (1992). "Gender, Metaphor, and the Definition of Economics." Economics and Philosophy 8: 103-125.

Nelson, Julie A. (2012). Are Women Really More Risk-Averse than Men? . INET Resarch Note.

Nickerson, Raymond S. (1998). "Confirmation Bias: A Ubiquitous Phenomenon in Many Guises." Review of General Psychology 2(2): 175-220.

Nosek, Brian, Mahzarin Banaji, et al. (2007). "'Gender-Science IAT"." from https://implicit.harvard.edu/implicit/.

Novemsky, Nathan and Daniel Kahneman (2005). "The Boundaries of Loss Aversion." Journal of Marketing Research 42(2): 119-128.

O'Neil, James M. (2008). "Summarizing 25 Years of Research on Men's Gender Role Conflict Using the Gender Role Conflict Scale: New Research Paradigms and Clinical Implications." The Counseling Psychologist 36: 358-.

Olsen, Robert A. and Constance M. Cox (2001). "The Influence of Gender on the Perception and Response to Investment Risk: The Case of Professional Investors." The Journal of Psychology and Financial Markets 2(1): 29-36.

Plant, E. Ashby, Janet Shibley Hyde, et al. (2000). "The Gender Stereotyping of

Emotions." Psychology of Women Quarterly 24(1): 81-92.

Plumwood, Val (1993). Feminism and the Mastery of Nature. London, Routledge. 
Ronay, Richard and Do-Yeong Kim (2006). "Gender differences in explicit and implicit risk attitudes: A socially facilitated phenomenon." British JOurnal of Social Psychology 45(2): 397-419.

Sen, Amartya (1992). Objectivity and Position. The Lindley Lecture, University of Kansas.

Sokol-Hessner, Peter, Colin F. Camerer, et al. (2013 (March, online publication)). "Emotion regulation reduces loss aversion and decreases amygdala responses to losses." Social Cognitive and Affective Neuroscience.

Uhlmann, Eric Luis and Geoffrey L. Cohen (2007). "“I think it, therefore it's true": Effects of self-perceived objectivity on hiring discrimination." Organizational Behavior and Human Decision Processes 104: 207-223. 